\title{
A survey of gross pathologic conditions in cull cows at slaughter in the Great Lakes region of the United States
}

\author{
D. J. Rezac, ${ }^{\star 1}$ D. U. Thomson,$\dagger^{2}$ M. G. Siemens, $\ddagger$ F. L. Prouty,§ C. D. Reinhardt,\# and S. J. Bartle† \\ *Department of Diagnostic Medicine/Pathobiology, and \\ †Department of Clinical Sciences, Kansas State University College of Veterinary Medicine, Manhattan 66506 \\ ‡Cargill Inc., Wichita, KS 67214 \\ $\S Z$ Zetis Animal Health, Florham Park, NJ 07932 \\ \#Department of Animal Sciences and Industry, Kansas State University, Manhattan 66506
}

ABSTRACT

The prevalence and severity of multiple gross pathologic lesions and abnormalities in cull dairy and beef cows was evaluated at a commercial abattoir in the Great Lakes region of the United States; 1,461 cattle were examined at slaughter over the course of 3 production days and evaluated for the occurrence and severity of lung, liver, rumen, and carcass abnormalities and pathologies. Of the 1,461 cattle examined at slaughter, $87 \%$ were classified as Holstein cows and $13 \%$ were classified as other cows. Liver abscesses were observed in $32 \%$ of the population and over half were classified as severe ( $18.5 \%$ population prevalence). The frequency distribution of cattle observed with a liver abscess was not different among production days. Severe ruminal lesions and rumenitis scars were observed in $10.0 \%$ of the population, and $25.1 \%$ of cattle were observed to have short or denuded papillae. Severe bovine respiratory disease complex lesions were observed in $10.3 \%$ of cattle. The most common reason for USDA postmortem carcass condemnation was malignant lymphoma (9 of 41 ). Only $45.9 \%$ of carcasses were free from bruising. Results indicate that ruminal acidosis and bovine respiratory disease complex occur at a relatively high frequency in this population. Although cows are routinely culled for reproductive failure or low milk production, the underlying reason may be causally related to these relatively prevalent conditions. Further investigation is warranted to assess this relationship and to examine the use of specific health intervention strategies within this demographic of cattle.

Key words: cull cow, bovine respiratory disease, ruminal acidosis, carcass bruising

Received October 22, 2013.

Accepted March 20, 2014.

${ }^{1}$ Current address: Midwest Veterinary Services Inc., Oakland, NE 68045 .

${ }^{2}$ Corresponding author: dthomson@vet.ksu.edu

\section{INTRODUCTION}

The culling of dairy or beef cattle from their respective herds is an unavoidable, necessary, and humane practice that ensures animals are not kept past their productive and healthy lifespan. To ensure a safe and wholesome food supply, this practice must be carried out in a timely and effective manner that does not allow animals to reach a point of poor and nontransportable condition.

The sale of cows that are no longer able to effectively conceive, carry, and wean a calf or produce milk contributes significantly to the beef supply. In 2012, $19.9 \%$ of the total number of federally inspected cattle in the United States for slaughter were characterized as cows ( $9.6 \%$ dairy cows, $10.3 \%$ other cows) by the USDA Food Safety and Inspection Service (USDA, 2013). The sale of cull animals by producers contributes 4 to $20 \%$ of operational gross revenue for both beef and dairy operations (Roeber et al., 2000). In addition to the economic benefit of the replacement of an animal that is no longer capable of profitability and given the steady decline of the US cattle inventory (USDA-NASS, 2013), the value of these animals for all purposes is likely to increase. Public concerns and attitudes regarding the care and health of animals entering the food chain are an increasingly important consideration as are environmental concerns for the nature of land use, water use, and waste management throughout a food animal's life cycle; therefore, it is necessary to correctly identify opportunities to improve animal well-being at every step in the food supply chain, including production, culling, and harvest. Furthermore, collecting and monitoring objective data that are correlated with common production-related diseases and practices provides useful information to many parties.

Culling is often carried out in a nonprogrammed and relatively subjective manner (Lehenbauer, 1998); however, it is important to correctly identify the causative factors that contribute to cows leaving the herd. It is only then that specific and judicious interventions can 
be introduced into a production system to effectively improve the health, well-being, and long-term profitability of cows in dairy or beef operations. McConnel et al. (2009) proposed that necropsies be performed to identify causative factors in mortalities on dairy farms. Those authors observed that producers correctly identified the cause of mortalities in $55 \%$ of the cases; however, if cases that involved traumatic accidents and locomotive disorders were removed from the data set, a correct mortality diagnosis was made in only $41 \%$ of cases.

On-farm mortality is a critical dynamic to understand when developing appropriate intervention strategies; equally as important to the herd health and welfare are the factors that may have led to culling. Multiple reports have outlined gross trends in reasons for culling in US and Canadian dairy herds (Martin et al., 1982; Bascom and Young, 1998; Hadley et al., 2006). In most cases, it is likely that culling is carried out in a different manner and with a different set of parameters on dairy versus beef farms. Unfortunately, information relating to culling in beef cattle herds is limited, but a single report does cite old age and bad teeth as a primary reason (USDA-APHIS, 2013).

Ruminal acidosis affects both fed beef cattle and dairy cows. Accurate diagnosis of ruminal acidosis, either clinical or subacute ruminal acidosis (SARA), enabling management changes is challenging. Common consequences of ruminal acidosis in dairy cows are decreased DMI, milk fat depression, reduced fiber digestion, loss of body condition, diarrhea, laminitis, rumenitis, liver abscesses, and culling (Kleen et al., 2003; Plaizier et al., 2008). Studies have attempted to estimate the occurrence of SARA in herds by utilizing $\mathrm{pH}$ measurements of ruminal fluid collected via rumenocentesis along with a structured sampling procedure (Garrett et al., 1999); however, such monitoring is not a common practice within the industry. In fed beef cattle, liver abscesses, a sequela to ruminal acidosis, are commonly diagnosed at slaughter (Nagaraja and Chengappa, 1998). These objective data can be used to gauge nutritional, health, and managerial practices and to drive intervention strategies. The opportunity exists at the time of culling to collect similar data on cows.

Examination of the interior of the rumen at the time of slaughter may also be a valuable diagnostic tool for nutritional health. The occurrence of rumenitis lesions at slaughter has been associated with significant decreases in beef cattle performance (Thompson et al., 2008; Rezac, 2013). Once the rumen epithelium is compromised and morphologic changes occur, the absorptive capacity of the affected tissue is lost, which may further exacerbate the accumulation of VFA or lactic acid (Kleen et al., 2003). Conversely, hepatic abscesses have been shown to resolve into scars within 50 to $70 \mathrm{~d}$ after portal inoculation with Fusobacterium necrophorum (Itabisashi, 1987). Therefore, monitoring both the rumen and the liver for lesions and abscesses may provide a more complete diagnostic tool for ruminal acidosis than liver abscesses alone.

Bovine respiratory disease complex (BRDC), although normally approached as a problem limited to younger cattle exposed to risk factors and stressors such as weaning, transportation, and commingling (Maillard et al., 2006; Snowder et al., 2006) also affects older cows. Data suggest that pneumonia is the second leading cause of postmortem carcass condemnations in dairy cows (White and Moore, 2009) and a leading proximate cause of death in postmortem examinations of dairy cattle (McConnel et al., 2009). The sensitivity and specificity of traditional diagnosis of BRDC in fed beef cattle using clinical scoring alone has been estimated to be 61.8 and $62.8 \%$, respectively. Utilizing lung lesions at harvest for BRDC diagnosis improves sensitivity and specificity to 77.4 and $89.7 \%$, respectively (White and Renter, 2009). Therefore, monitoring lungs in cull cows for signs of pulmonary lesions at slaughter may yield valuable information for veterinarians and other herd health personnel who control management and health intervention strategies.

Although not a production-related disease, bruising of cattle as a result of handling and transportation to harvest facilities is important for both welfare and economic reasons. Rosse (1974) estimated quantitative economic losses attributed to carcass bruises at $\$ 22.4$ million; however, this figure needs to be revisited due to the stark changes in production, transportation, and management that have occurred since the 1970s. Nevertheless, bruising is also an indication of compromised welfare (Jarvis et al., 1996) and should be included as an objective measurement in a comprehensive animal welfare monitoring program.

The objectives of this study were to investigate the prevalence of multiple gross pathologies at slaughter in cull cattle at a commercial abattoir in the Great Lakes region of the United States, and to provide data regarding the prevalence of important production-related diseases and defects in cull cattle.

\section{MATERIALS AND METHODS}

Animal care and use committee approval was not required nor requested for the methods used in this study because no live animals were used.

Cattle were enrolled into the study via communication between the cooperating abattoir and Kansas State University (Manhattan). Cattle originated from several sources in the Great Lakes and northern Midwest re- 
gions of the United States. In total, 1,461 carcasses were examined at slaughter over the course of the majority of one shift on 3 separate, consecutive production days from May 28 to May 30, 2013, and were evaluated for the occurrence and severity of multiple gross pathology lesions and abnormalities.

A team of trained investigators comprising undergraduate, graduate, and veterinary students was dispatched to a single commercial abattoir in the Great Lakes region to gather gross pathology data. Before gathering data, all personnel were trained utilizing a combination of self-study and instructor-led training material on all data collection procedures. The same crew of personnel was used for the entirety of the data collection, and each crew member's assignment remained constant. For lung, liver, and bruising scores, each measurement was attributable to individual carcass.

Lung scores were assigned by visually evaluating lungs as they passed by a single investigator stationed along the offal table. Lungs were scored on a 3-point scale similar to that of Thompson et al. (2006): normal $=$ no visible gross pathological evidence of lesions associated with BRDC; mild $=<50 \%$ consolidation of any single lung lobe with lesions associated with BRDC; severe $=>50 \%$ consolidation of any single lung lobe with lesions associated with BRDC or any sign of pleural adhesion to the thoracic cavity. Although lesions occurring in any portion of the lung were noted and assigned a score, personnel were trained to make careful a diagnosis of the right cranial and middle lobes; previous investigation has shown that $>86 \%$ of lesions are detected only when evaluating those anatomical locations (Epperson, 2003).

Livers were evaluated for abnormalities by a single investigator stationed along the offal table. Hepatic abscesses were scored using a modified Elanco Liver Check System (Elanco Animal Health, Greenfield, IN). Livers that were deemed free from abscesses, parasites, or other pathological abnormalities were classified as normal. An $\mathrm{A}-$ was assigned to livers that displayed $\leq 2$ abscesses $\leq 2 \mathrm{~cm}$ in diameter, or resolved abscess scars; an A designation was assigned to livers displaying 2 to 4 abscesses 2 to $4 \mathrm{~cm}$ in diameter; an $\mathrm{A}+$ was assigned to livers displaying $\geq 1$ abscesses $>4 \mathrm{~cm}$ in diameter or $>4$ abscesses $>2 \mathrm{~cm}$ in diameter. Abscesses adhered to the diaphragm, other organs, or the abdominal cavity were noted and classified as A+A. Likewise, abscesses that were ruptured or open, leading to the condemnation of all offal for the respective carcass, were scored as $\mathrm{A}+\mathrm{O}$. Livers with adhesions and ruptured abscesses were denoted as an $\mathrm{A}+\mathrm{AO}$. For the purposes of this report, however, $\mathrm{A}+\mathrm{A}, \mathrm{A}+\mathrm{O}$, and $\mathrm{A}+\mathrm{AO}$ scores were consolidated into the A+ category for prevalence and performance association data. The occurrence of other abnormalities, including liver flukes and other parasites, telangiectasia (of all degrees), hepatic lipidosis (fatty liver), and cirrhosis, as well as livers condemned due to contamination or miscellaneous criteria were recorded.

The ruminal mucosa was evaluated for the presence of gross pathological lesions associated with ruminal acidosis. Following evisceration, each rumen was drained of digesta and hung on the processing chain per normal plant procedures. Gross pathological diagnosis was accomplished in teams of 2: one crew member palpated and manipulated the rumen to allow for thorough inspection of the lumen and verbally dictated a score to a recorder. Scores were assigned according to the following system: normal $=$ gross appearance of healthy epithelium with thick, lush papillae with no signs of inflammation, ulceration, or other insult; mild $=$ consolidated portions of the ruminal mucosal surface displaying short (relative to normal) or denuded papillae; and severe = active rumenitis lesions; focal or multifocal ulcerations characterized by demarcated, irregularly circular, depressed, red, foci or healed ulcerations (scars) characterized by focal or multifocal puckered scars (star shaped) devoid of papillae (Thomson, 1967). Rumens condemned by USDA inspection were not assigned a score or included in the prevalence data.

Carcass bruises were assessed by a single investigator stationed along the production line after the hide was removed and before the carcass was split. The location of the bruise was noted according to a predetermined grid with 9 possibilities (Figure 1) and a number assigned according to denote the location of the bruise. The anatomical borders and landmarks for the respective numbers were as follows: (1) right hind limb: cranial border is a transverse line at the level of the lumbosacral junction and extends caudally including the distal right hind limb. The medial border of this region bisects the round on the right hindquarter. (2) Midline tailhead: cranial border beginning at the lumbosacral junction and extending caudally. Lateral borders bisect the left and right rounds. (3) Left hind limb: cranial border is a transverse line at the level of the lumbosacral junction and extends caudally including the distal left limb. The medial border of this region bisects the round on the left hindquarter. (4) Right barrel: cranial border is a transverse line at the level of the seventh thoracic vertebrae extending caudally to a transverse line at the lumbosacral junction. The medial border of this region is the lateral border of the right epaxial muscles. (5) Midline barrel: cranial border beginning at the seventh thoracic vertebrae extending caudally to the lumbosacral junction. (6) Left barrel: cranial border is a transverse line at the level of the seventh thoracic vertebrae extending caudally to a transverse line at the lumbosacral junction. The medial 
border of this region is the lateral border of the left epaxial muscles. (7) Right forelimb: caudal border is a transverse line at the sixth thoracic vertebrae extending cranially including the distal right forelimb. The medial border of this region bisects the chuck on the right side. (8) Midline shoulder: caudal border is at the level of the sixth thoracic vertebrae and extends cranially. Lateral borders of this region bisect the left and right chuck. (9) Left forelimb: caudal border is a transverse line at the sixth thoracic vertebrae extending cranially including the distal left forelimb. The medial border of this region bisects the chuck on the left side. For the purposes of this report, grid location numbers were transcribed into gross anatomical areas of interest (e.g., the hip, back). In addition to the location of each bruise, 1 of 3 severity scores was assigned as follows: mild $=<19.3 \mathrm{~cm}^{2}(<3$ in. $^{2}$ ) of affected surface area; moderate $=19.3$ to 180.6 $\mathrm{cm}^{2}$ (3 to $28 \mathrm{in}^{2}$ ) of affected surface area; or severe $=$ $>180.6 \mathrm{~cm}^{2}\left(>28 \mathrm{in}^{2}{ }^{2}\right)$ of affected surface area.

A calculation to determine the sample size needed for surveying the frequency of severe BRDC lung lesions in a population was completed a priori according to Scheaffer et al. (1990) using the following inputs: population size $=6.5$ million, anticipated percentage frequency of event $=10 \%$, confidence limits $= \pm 5 \%$, and a design effect adjustment factor of 10 to account for cluster sampling. A total of 1,383 (95\% confidence level) cattle were determined to be needed. Following collection, data were entered into, stored, and managed using a computer-based database program (Excel for Windows 2010; Microsoft Corp., Redmond, WA). Frequency dis-

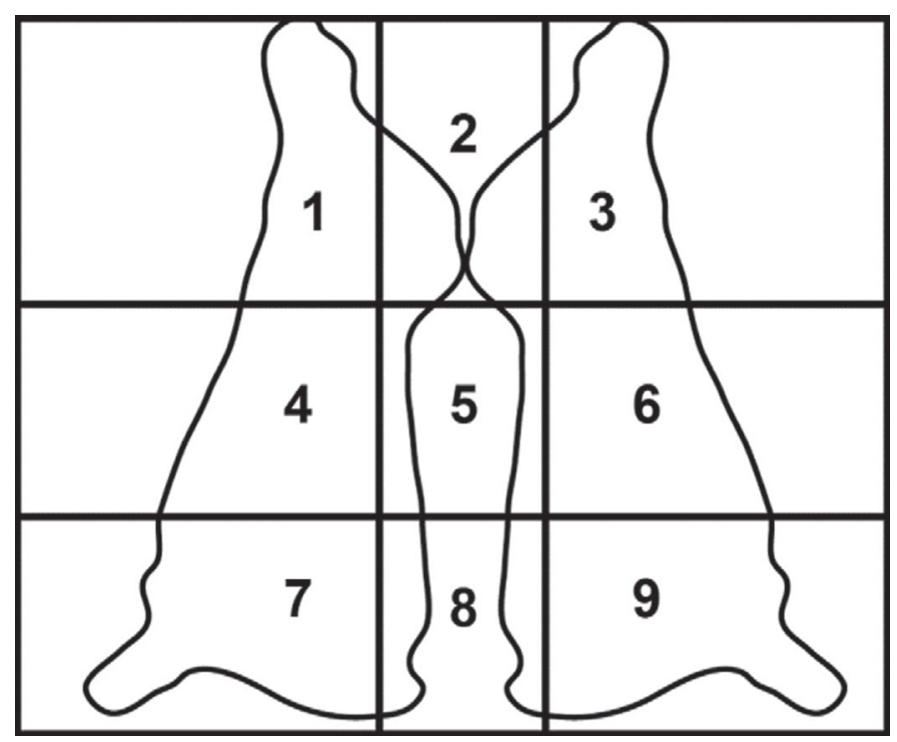

Figure 1. Anatomical location grid depicting the 9 grid location designations that can be assigned to a bruise observed on a bovine carcass. tributions, contingency tables, odds ratios, and their respective $95 \%$ CI were calculated using a computerbased statistical analysis software (Proc Freq of SAS, version 9.3; SAS Institute Inc., Cary, NC); differences among frequency distributions were assessed utilizing the chi-square $\left(\chi^{2}\right)$ test for homogeneity. Significance was declared at $P \leq 0.05$.

\section{RESULTS}

Of the 1,461 cattle examined at slaughter, $87 \%$ were classified as Holsteins, presumably all from dairy operations, whereas $13 \%$ were classified as other cows. Thirty-five percent of the total study population was observed on d $1,45 \%$ on $\mathrm{d} 2$, and $20 \%$ on $\mathrm{d} 3$. On d 1, $92 \%$ of population was classified at Holsteins, followed by 79 and $94 \%$ on d 2 and 3 of data collection, respectively.

Thirty-two percent of cattle were observed to have a liver abscess of varying severity and over half of these (18.5\% of total) were severe in nature (Table 1$)$. The frequency distribution of cattle observed with a liver abscess did not differ among production days $(P=$ $0.86)$. A vast majority of the severe abscesses $(90 \%)$ were observed with at least one abscess adhered to the diaphragm, body wall, or other organ. Relatively few cattle were observed with more than one gross liver pathological abnormality (3 animals, total); however, animals with more severe conditions such an $\mathrm{A}+$ abscess with an adhesion may have masked other less pronounced gross lesions.

Rumen health scores are shown in Table 2. Overall, $35 \%$ of the population was observed with some kind of rumen epithelium abnormality. The frequency distribution of cattle observed with a rumen epithelium abnormality was different among production days $(P<$ 0.01 ) and was $25.7,39.1$, and $47.6 \%$ for d 1,2 , and 3 , respectively. The most prevalent abnormality was denuded, sparse, or short papillae (25.1\%). Lesions were found almost invariably on the luminal ventral surface of the ventral sac as well as the luminal ventral surface of the caudodorsal blind sac.

Pulmonary lesions associated with BRDC were observed in $33.8 \%$ of all cattle (Table 3). Mild lesions ( $\leq 50 \%$ consolidation of any lung lobe) were the most common and were found in $23.5 \%$ of cattle. The frequency distribution of cattle with a BRDC lesion was not different among production days $(P=0.59)$. The odds of a lung lesion given the presence of a liver abscess were not significantly different than the odds given of a lung lesion when no abscess was present (odds ratio $1.09,95 \%$ CI: 0.86 to $1.37 ; P=0.48$ ), and $33.4 \%$ of cattle with a liver abscess also had a lung lesion, 
Table 1. Frequency and percentage prevalence of hepatic abscesses and abnormalities in cull cows at slaughter in the Great Lakes region of the United States

\begin{tabular}{lcccc}
\hline $\begin{array}{l}\text { Liver } \\
\text { score }^{1}\end{array}$ & Frequency & Percentage & $\begin{array}{c}\text { Cumulative } \\
\text { frequency }\end{array}$ & $\begin{array}{c}\text { Cumulative } \\
\text { percentage }\end{array}$ \\
\hline Normal & 656 & 44.9 & 656 & 44.9 \\
A- & 103 & 7.1 & 759 & 52.0 \\
A & 95 & 6.5 & 854 & 58.5 \\
A & 271 & 18.6 & 1,125 & 77.0 \\
A and parasite & 1 & 0.1 & 1,126 & 77.1 \\
Fatty liver & 46 & 3.2 & 1,172 & 80.2 \\
Fatty liver and parasite & 2 & 0.1 & 1,174 & 80.4 \\
Parasite & 90 & 6.2 & 1,264 & 86.5 \\
Telangiectasia & 15 & 1.0 & 1,279 & 87.6 \\
Contamination & 105 & 7.2 & 1,384 & 94.7 \\
Cirrhosis & 2 & 0.1 & 1,386 & 94.9 \\
Unknown & 28 & 1.9 & 1,414 & 96.8 \\
Miscellaneous & 47 & 3.2 & 1,461 & 100.0
\end{tabular}

${ }^{1}$ Gross liver pathology at slaughter: normal = livers free from abscesses, parasites, or other pathological abnormalities; $\mathrm{A}-=$ livers that displayed $\leq 2$ abscess $\leq 2 \mathrm{~cm}$ in diameter, or resolved abscess scars; $\mathrm{A}=$ livers that displayed 2 to 4 abscesses 2 to $4 \mathrm{~cm}$ in diameter; $\mathrm{A}+=$ livers displaying $\geq 1$ abscesses $>4 \mathrm{~cm}$ in diameter or $>4$ abscesses $>2 \mathrm{~cm}$ in diameter, adhesions to the body wall or other organs, or a ruptured abscess; fatty liver $=$ liver displaying gross evidence of hepatic lipidosis; telangiectasia $=$ livers displaying gross pathologic evidence of telangiectasia; parasite = livers displaying evidence of infestation by flukes (Fascioloides magna or other); contamination $=$ liver condemned for contamination (e.g., hair, digesta); cirrhosis $=$ livers displaying gross pathologic evidence of cirrhosis; unknown $=$ diagnosis of the liver was not carried out; miscellaneous $=$ liver condemned for miscellaneous reasons.

whereas $68.5 \%$ of cattle that did not have a lung lesion did not have a liver abscess.

The frequency of carcasses condemned due to USDA postmortem inspection was also determined. Overall, $2.8 \%$ of the population (41 animals) was condemned due to USDA Food Safety and Inspection Service veterinary medical officer postmortem inspection. The specific diagnoses (reasons for condemnation) are given in Table 4. The most frequent reasons for postmortem condemnation were malignant lymphoma $(9 / 41)$, abscess/pyemia (8/41), and septicemia $(8 / 41)$.

Table 2. Frequency and percentage prevalence of rumen epithelial health scores in cull cattle at slaughter in the Great Lakes region of the United States $(\mathrm{n}=1,048)$

\begin{tabular}{lcccc}
\hline $\begin{array}{l}\text { Rumen } \\
\text { score }^{1}\end{array}$ & Frequency & Percentage & $\begin{array}{c}\text { Cumulative } \\
\text { frequency }\end{array}$ & $\begin{array}{l}\text { Cumulative } \\
\text { percentage }\end{array}$ \\
\hline Normal & 679 & 64.8 & 679 & 64.8 \\
Mild & 263 & 25.1 & 942 & 89.9 \\
Severe & 30 & 2.9 & 972 & 92.8 \\
Scar & 74 & 7.1 & 1,046 & 99.8 \\
Unknown & 2 & 0.2 & 1,048 & 100.0 \\
\hline
\end{tabular}

${ }^{1}$ Gross rumen pathology at slaughter: normal = gross appearance of healthy epithelium with thick, lush papillae with no signs of inflammation, ulceration, or other insult; mild = consolidated portions of the ruminal mucosal surface displaying short (relative to normal) or denuded papillae; severe $=$ active rumenitis lesions, focal or multifocal ulcerations characterized by demarcated, irregularly circular, depressed, red, foci; scar $=$ healed ulcerations (scars) characterized by focal or multifocal puckered scars (star-shaped) devoid of papillae (Thomson, 1967); unknown = diagnosis of the rumen was not carried out.
Some degree of bruising was observed on $54.1 \%$ of carcasses (Table 5). The frequency distribution of carcasses with a bruise differed by production day $(P<$ 0.01 ) and was $43.6,54.5$, and $70.3 \%$ for $\mathrm{d} 1,2$, and 3 , respectively. Bruises were observed on the hip region of $36.5 \%$ of carcasses and on the back of $24.3 \%$ of carcasses. Overall, $11.6 \%$ of carcasses were affected by at least one severe bruise $\left(>180.6 \mathrm{~cm}^{2}\right.$ of affected surface area). Furthermore, a carcass was more likely to have a back bruise if a hip bruise was also present (odds ratio $2.2,95 \%$ CI: 1.75 to $2.84 ; P=0.01$ ), and $33.9 \%$ of cattle with a hip bruise also had a back bruise, whereas $81.3 \%$ of cattle that did not have a hip bruise did not have a back bruise.

Table 3. Frequency and percentage prevalence of bovine respiratory disease complex (BRDC)-associated lesions in cull cattle at slaughter in the Great Lakes region of the United States

\begin{tabular}{lcccc}
\hline $\begin{array}{l}\text { Lung } \\
\text { score }^{1}\end{array}$ & Frequency & Percentage & $\begin{array}{c}\text { Cumulative } \\
\text { frequency }\end{array}$ & $\begin{array}{c}\text { Cumulative } \\
\text { percentage }\end{array}$ \\
\hline Normal & 949 & 65.0 & 949 & 65.0 \\
Mild & 343 & 23.5 & 1,292 & 88.4 \\
Severe & 151 & 10.3 & 1,443 & 98.8 \\
Unknown & 18 & 1.2 & 1,461 & 100.0 \\
\hline
\end{tabular}

${ }^{1}$ Gross lung pathology at slaughter: normal $=$ no visible gross pathological evidence of lesions associated with BRDC; mild $=<50 \%$ consolidation of any single lung lobe with lesions associated with BRDC; severe $=>50 \%$ consolidation of any single lung lobe with lesions associated with BRDC or any sign of pleural adhesion to the thoracic cavity; unknown = diagnosis of the lungs was not carried out. 
Table 4. Frequency and percentage prevalence of USDA diagnosis (by USDA Public Health veterinarian) and reason for postmortem carcass condemnation in 41 cull cows at slaughter in the Great Lakes region of the United States

\begin{tabular}{lcccc}
\hline $\begin{array}{l}\text { USDA } \\
\text { diagnosis }\end{array}$ & Frequency & Percentage & $\begin{array}{c}\text { Cumulative } \\
\text { frequency }\end{array}$ & $\begin{array}{c}\text { Cumulative } \\
\text { percentage }\end{array}$ \\
\hline Abscess/pyemia & 8 & 19.5 & 8 & 19.5 \\
Carcinoma & 2 & 4.9 & 10 & 24.4 \\
Icterus & 2 & 4.9 & 12 & 29.3 \\
MD and DC & 2 & 4.9 & 14 & 34.1 \\
Malignant lymphoma & 9 & 22.0 & 23 & 56.1 \\
Pericarditis & 4 & 9.8 & 27 & 65.9 \\
Peritonitis & 4 & 9.8 & 31 & 75.6 \\
Pneumonia & 2 & 4.9 & 33 & 80.5 \\
Septicemia & 8 & 19.5 & 41 & 100.0 \\
\hline
\end{tabular}

${ }^{1}$ Miscellaneous degenerative and dropsic condition.

\section{DISCUSSION}

In 2012, dairy cows accounted for approximately $48 \%$ of all federally inspected cows slaughtered in the United States $(9.6 \%$ of the total head slaughtered; USDA, 2013). Therefore, it should be noted that the population investigated in this study does not represent the demographics of the United States as a whole, but focuses on cull cows originating from dairies. Published peer-reviewed data concerning the prevalence and severity of gross lesions in cull cattle at slaughter are limited. Ahola et al. (2011) completed a comprehensive survey of various quality defects in beef and dairy cows and bulls sold through livestock auction markets in the western United States; however, only exterior defects and lesions were noted. Furthermore, the National Beef Quality Audit (NBQA), which does report data on liver condemnations, lung lesions, and carcass bruising, does not include data from cull cows (McKeith et al., 2012).

Dairy cows are at risk for developing ruminal acidosis both due to the rapid change in diet (from low to high proportion of nonstructural carbohydrates) when transitioning through the various stages of the production period (i.e., gestating to lactating) and to the quantitatively large DMI of high-energy diets observed in high-producing dairy cows. Liver abscesses are common sequelae to ruminal acidosis when the rumen epithelium is damaged by a high concentration of organic acids and low $\mathrm{pH}$. The $32.2 \%$ prevalence of liver abscess reported in this study is a $570 \%$ increase over that reported by the most recent NBQA (2011) in fed cattle (4.8\%; McKeith et al., 2012) and a 128\% increase compared with the prevalence reported by the 2007 National Market Cow and Bull Beef Quality Audit (14\%; Hale et al., 2007). The high prevalence of liver abscess in cull cows is in contrast to perception of the problem within the veterinary and animal health community. As mentioned, little published data exists on the prevalence and severity of liver abscesses in cull cows, although proposals to conduct such an assessment have been made (Nagaraja and Smith, 2000). One published report does document liver abscesses in dairy cows at a veterinary teaching hospital over almost 12 yr; however, those data were derived from individual case reports as opposed to a large cross-sectional study that is more likely to represent the true prevalence in the population (Doré et al., 2007). A factor in the high prevalence observed in cull cows is the lack of specific interventions available for use in lactating dairy cows; antimicrobial feed additives such as tylosin, the most common intervention for liver abscesses in feedlot cattle (Nagaraja and Chengappa, 1998), are labeled only for use in beef cattle. Liver abscesses in cows can also be the result of traumatic reticuloperotonitis (Nagaraja and Smith, 2000; "hardware disease"). The etiopathogenesis for this condition involves puncture of the reticular wall by an ingested foreign body, usually metallic, and subsequent peritonitis, pericarditis, myocarditis, endocarditis, pleuritis, pneumonitis, liver abscess, or septicemia depending on the extent of trauma inflicted by the foreign body (Gokce et al., 2007). Because several of the carcasses condemned by postmortem USDA inspection were diagnosed with the above pathologies, it is likely that several of these animals suffered from hardware disease.

Table 5. Frequency and percentage prevalence of the number of bruises observed on the carcasses of cull cows at slaughter in the Great Lakes region of the United States $(\mathrm{n}=1,461)$

\begin{tabular}{lcccc}
\hline $\begin{array}{l}\text { No. of } \\
\text { bruises }\end{array}$ & Frequency & Percentage & $\begin{array}{c}\text { Cumulative } \\
\text { frequency }\end{array}$ & $\begin{array}{c}\text { Cumulative } \\
\text { percentage }\end{array}$ \\
\hline 0 & 671 & 45.9 & 671 & 45.9 \\
1 & 343 & 23.5 & 1,014 & 69.4 \\
2 & 265 & 18.1 & 1,279 & 87.5 \\
$3+$ & 182 & 12.5 & 1,461 & 100.0 \\
\hline
\end{tabular}


The rumen is the primary focus of infection in the rumenitis-liver abscess complex (Scanlan and Hathcock, 1983). Recently, Rezac (2013) reported 10.5\% of severe + scar ruminal health scores and $13.6 \%$ prevalence of mild rumen health scores in fed beef cattle, which is numerically less than the prevalence of mild rumen health scores observed here but the prevalence of severe + scars scores were similar. Clumping and irregular growth patterns in the ruminal papillae may indicate damage to the epithelium; however, common gross results of subacute or clinical acidosis include parakeratosis, blunted or denuded areas of papillae, and in more severe cases, ulceration of the epithelium and subsequent rumenitis lesions. The damaged ruminal wall is then subject to colonization by normally commensal microorganisms of the rumen including fungi and bacteria. The primary pathogen of interest is the gram-negative anaerobe Fusobacterium necrophorum, which can form emboli in the ruminal wall and be trans-located to the liver via portal circulation. In the liver, abscesses form as a result of the multifaceted virulence factors possessed by Fusobacterium necrophorum (Tadepalli et al., 2009). Given the high prevalence of liver abscesses in this population of cattle, a corresponding high prevalence of abnormal rumen health scores (mild, severe, and scars) would be expected. Unfortunately, matching of individual rumen scores with liver scores was not possible due to processing practices at the abattoir. The chronic form of the majority of the ruminal pathology (scars and consolidated expanses of denuded papillae) may suggest long-term exposure of the ruminal epithelium to an unfavorable environment. The frequency distribution of rumen abnormalities was significantly different by processing day; however, no causal factors are readily apparent. Variation in the source of animals or culling patterns and culling criteria over the course of the week are possible explanations.

Similar to liver and rumen pathology data, information in the published literature relating to BRDC in cull cows at slaughter is limited. Traditionally, intervention efforts for respiratory disease in cattle are focused on young, growing stock (Maillard et al., 2006). However, the lung lesion prevalence rates observed in the current study suggest that more attention to diagnosis and treatment may be required in dairy cows. Supporting this idea are the data from a necropsy-based longitudinal study of an individual US dairy, which observed that pneumonia (chronic and acute) was a leading cause of proximate death on the farm (McConnel et al., 2009). A question when discussing pulmonary lesions as a diagnostic indicator for BRDC is the age of the lesion itself (i.e., when did the disease occur?). Although aging of lesions (i.e., time at which the disease occurred) is difficult, the presence of a consolidated lesion likely indicates a case of lobar bronchopneumonia where irreversible structural change has taken place at some time point in the animal's life (Mosier, 2006). Hence, the possibility exists that a portion of these lesions could be a result of BRDC events experienced in calfhood or heifer development phase.

The overall bruising prevalence of $54.1 \%$ observed here is numerically less than that observed by the 2007 National Market Cow and Bull Beef Quality Audit (63.4\%). However, both were over twice the prevalence reported by the most recent NBQA in fed beef cattle (23\%; McKeith et al., 2012). Numerous sources of variation could contribute to the prevalence and severity of carcass bruises. Jarvis et al. (1996) examined the influence of source, sex class, and handling on bruising in cattle from 2 UK slaughterhouses. Overall prevalence of bruising was remarkably high (97\%), and cattle sourced from auction markets had a significantly higher median number of bruises per carcass than did cattle sourced directly from farms. Slaughter lots of heifers and bulls had the least amount of bruising at slaughter compared with lots of steers, mixed steers, and heifers within a common source. Similar sex classification influence was observed by Weeks et al. (2002), and the authors hypothesized this was likely due to several factors including hide thickness, fat depth, temperament, and response to stimuli. A significant positive correlation was found between the use of driving aids and the occurrence of bruising of multiple areas of the carcass. In the United States, Hoffman et al. (1998) examined the associations of carcass bruising with transportation distance to slaughter and reported that the carcasses of mature beef cows marketed through livestock auctions that conducted first-point testing for brucellosis had a greater number and severity of bruises compared with their cohorts sourced from ranches or auction markets not conducting first-point testing. This increase was exacerbated when cows were transported $>325 \mathrm{~km}$. The authors concluded that the repeated handling and restraint of the first-point tested cows resulted in the increased prevalence and severity of bruising. In the current study, we observed informally that the majority of cattle were transported in double-decker aluminum "cattle pots," which are typical for mass transportation of cattle in the United States. We also observed that many Holstein cows appeared to be too tall to negotiate several of the points within the trailers without striking either their hips or backs, which coincides with the high prevalence of bruises in both of the respective areas. Therefore, the design of high-capacity trailers for primary use by transportation entities that typically move cull cows to and from market may warrant further investigation. Although the overall prevalence of bruising was greater than expected, several of the 
above-mentioned sources of variation may have led to differences observed in the prevalence of bruising by day. A limitation of this data is that source and therefore transportation type and distance data were not collected. Additional study is indeed warranted to examine these parameters.

The high prevalence of lesions indicative of BRDC and ruminal acidosis suggests that significant levels of these diseases exist within the dairy production population. It is certainly apparent that additional investigation is warranted to correlate lesions at slaughter with several covariates of interest on the individual animal level, such as source, reason for departure from the herd, transportation, performance, and so on, as well as to collect information from other geographic locations and seasonal time points. The high prevalence of liver abscesses suggests that significant opportunity exists for application of specific interventions such as improved nutritional management and vaccines that stimulate immune response to Fusobacterium necrophorum. However, microbiological examination of liver abscesses should be carried out to identify the pathogens implicated in these instances. Given the high-profile public perception associated with this important and necessary sector of the industry, it would benefit all parties involved to invest additional time and resources to ensure the highest plane of health and well-being of cull cows, and to identify and address areas of opportunity.

\section{ACKNOWLEDGMENTS}

This study was supported by Zoetis Animal HealthOutcomes Research (Zoetis Animal Health, Florham Park, NJ) and by the Beef Cattle Institute (Kansas State University, Manhattan). The authors thank Kansas State University veterinary and graduate students Jacob Hagenmaier, Caitlyn Redding, Aaron Schaffer, and Erin Schwandt for their technical assistance in data collection.

\section{REFERENCES}

Ahola, J. K., H. A. Foster, D. L. VanOverbeke, K. S. Jensen, R. L. Wilson, J. B. Glaze Jr., T. E. Fife, C. W. Gray, S. A. Nash, R. R. Panting, and N. R. Rimbey. 2011. Survey of quality defects in market beef and dairy cows and bulls sold through livestock auction markets in the Western United States: I. Incidence rates. J. Anim. Sci. 89:1474-1483.

Bascom, S. S., and A. Young. 1998. A summary of the reasons why farmers cull cows. J. Dairy Sci. 81:2299-2305.

Doré, E., G. Fecteau, P. Hélie, and D. Francoz. 2007. Liver abscesses in Holstein dairy cattle: 18 cases (1992-2003). J. Vet. Intern. Med. 21:853-856.

Epperson, W. P. 2003. A preliminary assessment of lung lesion distribution in fed cattle. South Dakota Beef Report 15. Dept. Anim. Sci., South Dakota State Univ., Brookings.
Garrett, E. F., M. Pereira, K. Nordlund, L. Armentano, W. Goodger, and G. Oetzel. 1999. Diagnostic methods for the detection of subacute ruminal acidosis in dairy cows. J. Dairy Sci. 82:1170-1178.

Gokce, H. I., G. Gokce, and M. Cihan. 2007. Alterations in coagulation profiles and biochemical and haematological parameters in cattle with traumatic reticuloperitonitis. Vet. Res. Commun. 31:529-537.

Hadley, G. L., C. Wolf, and S. Harsh. 2006. Dairy cattle culling patterns, explanations, and implications. J. Dairy Sci. 89:2286-2296.

Hale, D., J. Savell, R. Delmore, D. Johnson, T. Pringle, W. Henning, R. Maddock, T. Lawrence, and J. Nicholson. 2007. National market cow and bull beef quality audit-2007: A survey of producerrelated defects. Final Report. National Cattlemen's Beef Association, Centennial, CO.

Hoffman, D. E., M. F. Spire, J. R. Schwenke, and J. A. Unruh. 1998 Effect of source of cattle and distance transported to a commercial slaughter facility on carcass bruises in mature beef cows. J. Am. Vet. Med. Assoc. 212:668-672.

Itabisashi, T. 1987. Ultrasonogram of hepatic abscess in cattle inoculated with Fusobacterium necrophorum. Japan. J. Vet. Med. 49:585-592.

Jarvis, A. M., C. D. A. Messer, and M. S. Cockram. 1996. Handling, bruising and dehydration of cattle at the time of slaughter. Anim. Welf. 5:259-270.

Kleen, J. L., G. A. Hooijer, J. Rehage, and J. P. T. M. Noordhuizen 2003. Subacute ruminal acidosis (SARA): A review. J. Vet. Med. A Physiol. Pathol. Clin. Med. 50:406-414.

Lehenbauer, T. W. 1998. Dairy cow culling strategies: Making economical culling decisions. J. Dairy Sci. 81:264-271.

Maillard, R., S. Assié, and A. Douart. 2006. Respiratory Disease in Adult Cattle. Unité Pathologie Du Bétail, Ecole Nationale Vétérinaire, Alfort, France.

Martin, S., S. Aziz, W. Sandals, and R. Curtis. 1982. The association between clinical disease, production and culling of Holstein-Friesian cows. Can. J. Anim. Sci. 62:633-640.

McConnel, C. S., F. Garry, J. Lombard, J. Kidd, A. Hill, and D. Gould. 2009. A necropsy-based descriptive study of dairy cow deaths on a Colorado dairy. J. Dairy Sci. 92:1954-1962.

McKeith, R. O., G. D. Gray, D. S. Hale, C. R. Kerth, D. B. Griffin, J. W. Savell, C. R. Raines, K. E. Belk, D. R. Woerner, J. D. Tatum, J. L. Igo, D. L. VanOverbeke, G. G. Mafi, T. E. Lawrence, R. J. Delmore, L. M. Christensen, S. D. Shackelford, D. A. King, T. L. Wheeler, L. R. Meadows, and M. E. O'Connor. 2012. National Beef Quality Audit-2011: Harvest-floor assessments of targeted characteristics that impact quality and value of cattle, carcasses, and by-products. J. Anim. Sci. 90:5135-5142.

Mosier, D. 2006. Progression of BRD lung lesions. Pages 55-69 in Proc. Mtg. Academy of Veterinary Consultants, Colorado Springs, CO. Acad. Veterinary Consultants, Overland Park, KS.

Nagaraja, T., and R. Smith. 2000. Liver abscesses in beef cattle: Potential for dairy monitoring? Page 65-68 in Proc. 33rd Annu. Conf. Am. Assoc. Bovine Pract., Rapid City, SD. American Association of Bovine Practitioners, Auburn, AL.

Nagaraja, T. G., and M. M. Chengappa. 1998. Liver abscesses in feedlot cattle: A review. J. Anim. Sci. 76:287-298.

Plaizier, J. C., D. O. Krause, G. N. Gozho, and B. W. McBride. 2008 Subacute ruminal acidosis in dairy cows: The physiological causes, incidence and consequences. Vet. J. 176:21-31.

Rezac, D. J. 2013. Gross pathology monitoring of cattle at slaughter. PhD Diss. College of Veterinary Medicine, Kansas State University, Manhattan. http://krex.k-state.edu/dspace/handle/2097/16386.

Roeber, D., K. Belk, G. Smith, J. Tatum, T. Field, J. Scanga, C. Smith, P. Mies, H. Foster, and T. Kennedy. 2000. Improving the consistency and competitiveness of market cow and bull beef; and, improving the value of market cows and bulls. Final Report of the National Market Cow and Bull Beef Quality Audit-1999. National Cattlemen's Beef Association, Englewood, CO

Rosse, J. C. 1974. Your stake in the $\$ 184,000,000$ tangible farm to cooler loss. Pages 47-51 in Proc. Livestock Conservation Institute, South St. Paul MN. 
Scanlan, C. M., and T. L. Hathcock. 1983. Bovine rumenitis-liver abscess complex: A bacteriological review. Cornell Vet. 73:288-297.

Scheaffer, R., W. Mendenhall, and L. Ott. 1990. Elementary Survey Sampling. 4th ed. Duxbury Press, Belmont, CA.

Snowder, G. D., L. Van Vleck, L. Cundiff, and G. Bennett. 2006. Bovine respiratory disease in feedlot cattle: Environmental, genetic, and economic factors. J. Anim. Sci. 84:1999-2008.

Tadepalli, S., S. K. Narayanan, G. C. Stewart, M. M. Chengappa, and T. G. Nagaraja. 2009. Fusobacterium necrophorum: A ruminal bacterium that invades liver to cause abscesses in cattle. Anaerobe 15:36-43.

Thompson, P. N., W. A. Schultheiss, and A. Hentzen. 2008. The effect of rumen mucosal lesions on growth in South African feedlot cattle. Page 12 in Proc. World Buiatrics Congr. Hungarian Vet. J., Budapest, Hungary.

Thompson, P. N., A. Stone, and W. A. Schultheiss. 2006. Use of treatment records and lung lesion scoring to estimate the effect of respiratory disease on growth during early and late finishing periods in South African feedlot cattle. J. Anim. Sci. 84:488-498.

Thomson, R. G. 1967. Rumenitis in cattle. Can. Vet. J. 8:189-192.

USDA. 2013. Livestock slaughter 2012 summary. Accessed Jul. 16, 2013. http://usda01.library.cornell.edu/usda/current/LiveSlauSu/ LiveSlauSu-04-22-2013.pdf.
USDA-APHIS (Animal and Plant Health Inspection Service). 2013. Culling practices in beef cow-calf operations. Accessed Jul. 17, 2013. http://www.aphis.usda.gov.er.lib.k-state.edu/animal_ health/nahms/beefcowcalf/downloads/beef97/Beef97_is_Culling Prac.pdf.

USDA-NASS (National Agricultural Statistics Service). 2013. Cattle inventory. Accessed Jul. 16, 2013. http://usda.mannlib.cornell. edu/usda/nass/Catt//2010s/2013/Catt-02-01-2013.pdf.

Weeks, C. A., P. W. McNally, and P. D. Warriss. 2002. Influence of the design of facilities at auction markets and animal handling procedures on bruising in cattle. Vet. Rec. 150:743-748.

White, B. J., and D. G. Renter. 2009. Bayesian estimation of the performance of using clinical observations and harvest lung lesions for diagnosing bovine respiratory disease in post-weaned beef calves. J. Vet. Diagn. Invest. 21:446-453.

White, T. L., and D. A. Moore. 2009. Reasons for whole carcass condemnations of cattle in the united states and implications for producer education and veterinary intervention. J. Am. Vet. Med. Assoc. 235:937-941. 